\title{
Cervical ectopic pregnancy: ultrasound diagnosis and conservative management
}

\author{
Nidhi Chauhan ${ }^{1}$, Priyanka Goyal ${ }^{1}$, Arjun Lal ${ }^{2}$, Jashan Chhatwal ${ }^{1}$, Saba Shamim ${ }^{1}$
}

\begin{abstract}
${ }^{1}$ Department of Obstetrics and Gynaecology, ${ }^{2}$ Radiodiagnosis, Himalayan Institute of Medical Sciences, Dehradun, Uttarakhand, India
\end{abstract}

Received: 03 August 2016

Accepted: 02 September 2016

\section{*Correspondence:}

Dr. Nidhi Chauhan,

E-mail: manumanan@ rediffmail.com

Copyright: ( $)$ the author(s), publisher and licensee Medip Academy. This is an open-access article distributed under the terms of the Creative Commons Attribution Non-Commercial License, which permits unrestricted non-commercial use, distribution, and reproduction in any medium, provided the original work is properly cited.

\begin{abstract}
An ectopic pregnancy is one in which the fertilized ovum is implanted and develops outside the normal endometrial cavity. Cervical ectopic pregnancy is a rare form of ectopic pregnancy and can be defined as implantation of blastocyst in the endocervix, below the internal os; representing less than $1 \%$ of all ectopic pregnancies. Ultrasound diagnosis of this abnormal pregnancy was first described by Raskin (1978); thus early diagnosis in either weakly or non-symptomatic women in the first trimester is done; allowing conservative management. A 35 year old female, gravida 4 with living 1 issue and 2 abortions presented with a history of continuous bleeding per vaginum for last 1.5 months. Outside ultrasound depicted single live fetus of 7 weeks in cervical canal. She had a history of undergoing medical termination of pregnancy by surgical procedure of dilatation and evacuation at private hospital for completion of abortion. There was a history of excessive bleeding post procedure and 2 units of blood transfusion; referred in anaemic state to our institute with pack in situ. Pack was removed after 24 hours and managed conservatively. On general examination tachycardia present, BP was normal and patient was haemodynamically stable. On palpation abdomen was soft, non-tender and no organomegaly noticed. Urine pregnancy test was positive, serum $\beta \mathrm{HCG}$ levels were raised, USG depicted heterogeneous collection in cervix. Injection methotrenate $(1 \mathrm{mg} / \mathrm{Kg}$ body wt.) given. $\beta \mathrm{hCG}$ repeated after 7 days; levels decreased significantly. Patient was improved symptomatically and bleeding stopped. Cervical pregnancy is a rare condition, if not diagnosed and treated early during the course of pregnancy can have hazardous complications. Thus early diagnosis and management is necessary for preserving patient's fertility without significant complications.
\end{abstract}

Keywords: Cervical ectopic pregnancy, Methotrexate, Conservative management

\section{INTRODUCTION}

Ectopic pregnancies one in which fertilized ovum is implanted and develops outside the normal endometrial cavity. Cervical ectopic pregnancy is a rare form of ectopic pregnancy $(<1 \%)$ where implantation of blastocyst occurs in the endocervix below the internal os. ${ }^{1}$ Mortality due to ectopic pregnancy has been reduced due to

- Early recognition of high risk cases.

- Trans vaginal sonography, serum $\beta$ HCG and laproscopy.
Ultrasound diagnosis of this abnormal pregnancy was first described by Raskin (1978); thus early diagnosis in first trimester allows conservative management. ${ }^{2}$

\section{CASE REPORT}

A 35 year old female, gravida 4, para 1, live 1 (LSCS 6 years back for failure to progress) and 2 abortions (both 1st trimester spontaneous abortions 2 and 3 years back respectively not followed by suction and evacuation ) presented with a history of continuous, painless bleeding per vaginum for last 1.5 months and heavy bleeding for 
last 3 days. Outside ultrasound at 2 months of gestation depicted single live fetus of 7 weeks in cervical canal, internal os closed and uterine cavity was empty. She had a history of undergoing medical termination of pregnancy by surgical procedure of dilatation and evacuation at private hospital. Immediately following the procedure she started bleeding heavily for which intra vaginal packing was done, 2 units PRBC transfused and referred to our institute with pack in-situ. No history of contraception. Past medical history was not significant. On general examination pulse rate was $120 / \mathrm{min}$, BP was $100 / 60$ mmhg, pallor ++ and was haemodynamically stable. On palpation abdomen was soft, non-tender and no lump noticed. On local examination-bleeding per vaginum was present but within normal limits. Urine pregnancy test was positive, haemoglobin-7.7 gms/dl, AB positive and serum $\beta$ HCG levels- $529 \mathrm{mIU} / \mathrm{ml}$. Immediate USG depicted heterogenous collection in cervix.

Decision of medical management was taken. Inj. methotrexate $50 \mathrm{mg} /$ meter square of body surface area was given on the day of admission. Vaginal pack removed after 24 hours of its insertion (bleeding + but within normal limits). 2 units PRBC transfused, repeat haemoglobin-9.93 gm/dl, serum $\beta$ HCG levels sent on 4 th and 7 th day of treatment. ( $>15 \%$ reduction in serum $\beta$ HCG levels).Patient was discharged in satisfactory condition (pulse rate-90/min, BP-110/70 mmhg and bleeding per vaginum- just spotting). She was advised to follow up after 1 week but she didn't turn up.

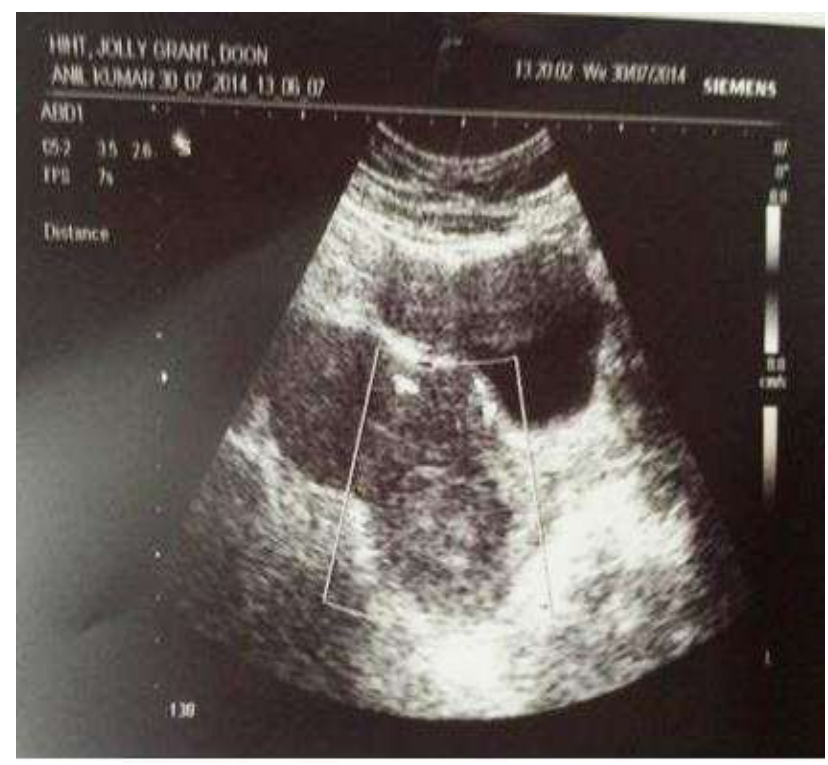

Figure 1: USG image depicting cervical pregnancy.

\section{DISCUSSION}

Incidence of cervical ectopic is approximately 1 in 9000 deliveries. ${ }^{1}$ In our case previous caesarean scar was the only risk factor. Usually the first complain is of painless vaginal bleeding and examination may reveal an open external cervical os with a fleshy mass protruding. Rubin established diagnostic criteria for cervical ectopic pregnancy (1983). ${ }^{2}$ Following are the criteria

- $\quad$ Soft, enlarged cervix equal to or larger than fundus.

- Uterine bleeding following amenorrhoea, without cramping pain.

- $\quad$ Products of conception entirely confined within and firmly attached to endocervix.

- A closed internal cervical os and a partially opened external os.

\section{Ultrasound Criteria for cervical pregnancy ${ }^{3}$}

- Echo-free uterine cavity or the presence of a false gestational sac only.

- Decidual transformation of the endometrium with dense echo structure.

- Diffuse uterine wall structure.

- Hourglass uterine shape.

- Ballooned cervical canal.

- Gestational sac in the endocervix.

- Placental tissue in the cervical canal.

- Closed internal os.

Sonography reveals the pregnancy in the cervical canal and an empty uterine cavity. Doppler helps to differentiate cervical pregnancy from intra uterine pregnancy. Confirmation is done by histological evidence of the presence of villi inside the cervical stroma. The most effective treatment of cervical pregnancy is unclear. Medical treatment -single or multiple dose intra muscular methotrexate is effective in 80-90\% cases of early cervical pregnancy. Medical management is more effective when-patient is

- Haemodynamically stable.

- $\quad$ Pretreatment $\beta$ hcg level $<3000 \mathrm{mIU} / \mathrm{ml}$.

- Absent cardiac activity.

In our case also we have given single dose of methotrexate. Potassium chloride intra amniotically can be given along with methotrexate when cardiac activity is present. Surgical therapy-dilatation and evacuation is a conservative surgical option, the main complication is high incidence of severe haemorrhage; which can be reduced by pre-operative measures such as-trans vaginal ligation of cervical branches of uterine arteries, cervical circlage, uterine artery embolization, intra cervical vasopressin injection, balloon catheter tamponade at the implantation site. Hemostatic sutures locally in the cervix, bilateral internal iliac artery or bilateral uterine artery ligation can be done. Hysterectomy is the last resort. Hysterectomy is the option for the females who have completed their families or have additional uterine pathology. 


\section{CONCLUSION}

Cervical pregnancy is a rare condition; if not diagnosed and treated early during the course of pregnancy can have hazardous complications-life threatening haemorrhage, differential diagnosis-cervical carcinoma, cervical or prolapsed submucousleiomyomas, trophoblastic tumor, placenta previa, and low-lying placenta. Adopting medical management as a first line treatment option offers the benefit of uterine preservation.

Funding: No funding sources Conflict of interest: None declared

Ethical approval: Not required

\section{REFERENCES}

1. Yankowitz J, Leake J, Huggins G, Gazaway P, Gates E. Cervical ectopic pregnancy: review of the literature and report of a case treated by single - dose methotrexate therapy. Obstet Gynecol Surv. 1990;45:405-14.

2. Hofmann HMH, Urdl W, Hofler H. Cervical pregnancy: case reports and current concepts in diagnosis and treatment. Arch Gynecol Obstet. 1987;241:63-9.

3. Mitra AG, Owens HM. Conservative medical management of advanced cervical ectopic pregnancies. Obstet Gynecol Surv. 2000;55:385-9.

Cite this article as: Chauhan N, Goyal P, Lal A,

Chhatwal J, Shamim S. Cervical ectopic pregnancy: ultrasound diagnosis and conservative management. Int J Reprod Contracept Obstet Gynecol 2016;5:3613-5. 